\title{
Analisis Karakteristik Kecepatan Motor Induksi (Asinkron) 3 Phasa Berdasarkan Pengaturan Torsi Terhadap Magnetic Break dan Rugi-Rugi Daya
}

\author{
Wawan Gunawan \\ Teknik Elektro Fakultas Teknik Universitas Pamulang Tangerang Selatan \\ J1. Surya Kencana No. 1 Pamulang Barat-Tangerang Selatan Banten \\ Telp./Fax. (021)7412566 \\ Email: wawangunawan 13@Yahoo.com,
}

\begin{abstract}
Abstrak
Motor listrik arus searah merupakan suatu alat yang berfungsi mengubah daya listrik arus searah menjadi daya mekanik. Motor induksi adalah jenis motor listrik tiga phasa yang banyak digunakan pada industri baik industri kecil, menengah, bahkan industri besar sekalipun, yakni untuk menggerakan mesin-mesin produksi. Salah satu masalah yang sering terjadi dalam menggunakan motor jenis ini adalah tingginya arus start motor, disamping itu perlunya mengetahui karakteristik dari motor yang akan digunakan dalam berbagai oprasi nya dan apa saja yang mempengaruhi unjuk kerja motor induksi, hal ini merupakan masalah yang serius bagi pemakai karena dengan tidak memahami tentang hal tersebut di atas akan berpengaruh terhadap biaya baik dari segi oprasional maupun perawatannya kelak. Berdasarkan pada masalah tersebut, pada penelitian ini penulis bermaksud untuk menganalisis karakteristik kecepatan motor induksi dan rugi-rugi daya yang terdapat pada motor induksi khusunya motor tipe rotor sangkar untuk dapat dijadikan sebagai salah satu pertimbangan untuk menentukan spesifikasi motor yang akan digunakan terhadap sistem proteksi yang akan dipasan, agar sesuai dengan kebutuhan adapun metoda yang akan digunakan untuk analisis karakteristik kecepatan dengan pengaturan torsi terhadap magnetic braek, sedangkan untuk rugi-rugi daya akan dilakukan dengan analisa pada rangkaian ekivalen dengan melakukan beberapa percobaan untuk memperoleh parameter rangkaian ekivalen tersebut

Kata kunci - Karakteristik motor induksi 3 Phasa, Rugi-rugi daya
\end{abstract}

\begin{abstract}
Abstrak
Direct current electric motor is a tool that serves to convert electric current direct power into mechanical power. An induction motor is a type of three phase electric motor that is widely used in industries both small, medium, and even large industries, namely to move the production machinery. One of the most common problems in using this type of motor is the high start current of the motor, besides the need to know the characteristics of the motor to be used in its various operations and what affect the performance of the induction motor, this is a serious problem for the user because by not understanding about the above will affect the cost both in terms of oprasional and later treatment. Based on the problem, in this study the authors intend to analyze the characteristics of induction motor speed and power losses contained in the induction motor, especially the motor type cage rotor to be used as one of the considerations to determine the specification of the motor to be used against the protection system that will in order to fit the requirements as for the method to be used for the analysis of velocity characteristics by setting torque to magnetic braek, whereas for the power losses will be done by analysis in equivalence circuit by doing some experiments to obtain the equivalence circuit parameters.
\end{abstract}

\section{PENDAHULUAN}

Motor induksi merupakan motor arus bolak balik yang paling banyak digunakan dalam berbagai aplikasi dimulai dari aplikasi dilingkungan rumah tangga sampai aplikasi di industri kecil maupun industri besar, motor induksi tiga phasa merupakan motor listrik yang paling umum digunakan dalam dunia industri dengan dua standar global yakni IEC dan NEMA. Motor Induksi IEC berbasis metrik (millimeter) sedangkan motor Induksi
NEMA berbasis imperial (inch), selain itu motor induksi baik yang 1 phasa maupun 3 phasa juga memiliki keunggulan dibanding dengan motor listrik lainnya, antara lain motor induksi mempunyai konstruksi yang sederhana, kokoh, harganya relatif murah, serta perawatannya yang mudah, sehingga motor induksi mulai menggeser penggunaan motor DC pada industri.

Sampai saat ini banyak digunakan motor induksi baik motor induksi satu phasa atau tiga phasa dalam kehidupan masyarakat luas. Oleh sebab itu perlu untuk diketahui bagaimana karakteristik dari motor tersebut, 
terutama pada motor induksi tiga phasa. Ada berbagai macam metoda dan cara yang dapat dilakukan dalm hal mengalisis motor-motor listrik 1 phasa maupun 3 phasa.

Dengan mengetahui karakteristik dari motor tersebut, maka masyarakat atau industri dapat mempertimbangkan bagaimana memilih motor induksi yang akan digunakan dalam kehidupan sehari - hari.

Dikarenakan pertimbangan-pertimbangan ini lah sehingga melatar belakangi penulis dapat menentukan sistem proteksi yang harus dipasang pada sistem kontrol, dan agar dapat menggambarkan bagaimana karakteristik kecepatan dan rugi - rugi pada motor induksi (Asinkron) 3 phasa yang akan di analisa, sebagai salah satu contoh dasar yang dapat digunakan oleh para teknisi sebelum memilih motor induksi yang akan diaplikasikan dalam kehidupan sehari-hari.

Sebelum menggunakan motor induksi baik satu phasa maupun tiga phasa sebaiknya kita ketahui terlebih dahulu karakteristik motor yang akan digunakan dan rugi - rugi daya apa saja yang di timbulkan oleh motor tersebut, karena dari karakteristik dan rugi - rugi itulah yang menunjukan kinerja motor induksi dalam berbagai kondisi oprasional nya, adapun karakteristik motor induksi yang perlu diperhatikan antara lain, karakteristik torsi-arus, karakteristik kecepatan-arus, karakteristik torsi-kecepatan, karakteristik arus-stator, karakteristik torsi elektromagnet, sedangkan rugi - rugi pada motor induksi diantara nya, rugi tembaga stator, rugi tembaga rotor, rugi gesekan angin serta daya mekanik yang ada.

Yang menjadi tujuan dalam penulisan tugas akhir ini adalah:

1. Untuk mengetahui kinerja motor induksi (asinkron) 3 phasa berdasarkan pengaturan torsi terhadap magnetik break.

2. Untuk mengetahui hal - hal apa saja yang mempengaruhi cara kerja dan karakteristik motor induksi (asinkron) 3 phasa.

3. Untuk mengetahui rugi - rugi apa saja yang ada pada motor induksi (asinkron) 3 phasa.

\section{METODA}

Pengujian yang dilakukan dalam penulisan tugas akhir ini yaitu untuk menentukan karakteristik kecepatan motor induksi (asinkron) 3 phasa dan menghitung rugi-rugi pada motor induksi (asinkron) 3 phasa khusus nya motor tipe rotor sangkar.

Untuk melakukan pengujian karakteristik dan rugi-rugi pada motor induksi ada beberapa metode yang dapat digunakan, oleh karena keterbatasan alat yang ada di BLK sehingga metode yang diusulkan dalam pengujian karakteristik motor induksi ini adalah dengan menggunakan metode pengaturan torsi terhadap magnetic break[5].

Dari pengujian ini nantinya akan diperoleh data-data yang terukur pada alat ukur terpasang dan nantinya akan dijadikan bahan untuk menganalisa karakteristik dan rugi-rugi pada motor induksi (asinkron) 3 phasa.

Sangat penting untuk mengetahui karakteristik dari sebuah motor induksi karena karakteristik suatu motor menunjukkan kinerja motor tersebut dalam berbagai kondisi operasi nya. Karakteristik motor listrik yang utama, yang perlu diperhatikan adalah diantaranya, karakteristik torsi-arus, karakteristik kecepatan-arus, dan karakteristik torsi-kecepatan. Motor induksi memiliki rugi-rugi daya karena di dalam motor induksi terdapat komponen tahanan tembaga dari belitan stator dan rotor, dan komponen induktor belitan stator dan rotor. Rugirugi pada motor induksi ini antara lain rugirugi tembaga, rugi inti, dan rugi karena gesekan dan hambatan angin.

\subsection{Pengujian Karakteristik Kecepatan Motor Induksi (Asinkron) 3 Phasa}

Pada pengujian ini seperti yang telah di jelaskan di atas penulis menggunakan motor induksi (asinkron) 3 phasa yang akan dianalisa serta tacho generator dan magnetick break yang akan dikopel pada motor induksi yang nantinya akan digunakan sebagai pengaturan torsi pada motor induksi, untuk mendapatkan nilai arus, tegangan, daya, frekwensi, cos phi dan kecepatan motor maka pada rangkaian pengujian perlu ditambahkan alat

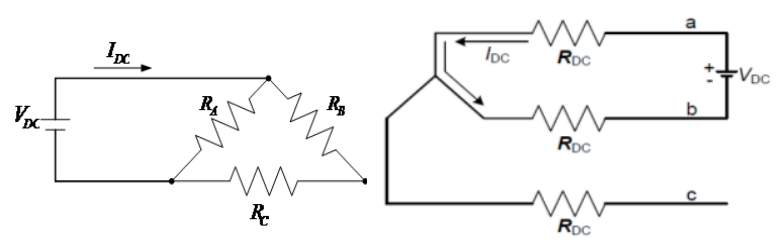

(B)

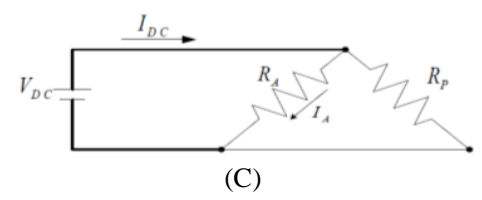

ukur seperti ampere meter, volt meter, watt meter, pengukur frekwensi, cos phi meter dan tacho meter, seperti yang terlihat pada Gambar 1. pengaturan torsi dilakukan dengan cara mengatur/menaikan torsi mulai dari $0 \mathrm{nM}$ lalu di naikan per $0,2 \mathrm{nM}$ dan mencatat datadata pada alat ukur yang terpasang, untuk menghindari agar tidak terjadi kerusakan pada motor dan peralatan yang digunakan oleh karena itu percobaan dilakukan dan dibatasi sampai alat ukur ampere meter menunjukan nilai arus maksimum dari motor yang di analisa. 


\subsection{Rugi-Rugi Pada Motor Induksi}

Untuk melakukan analisa atau perhitungan rugi-rugi pada motor induksi dilakukan dengan menggunakan metode

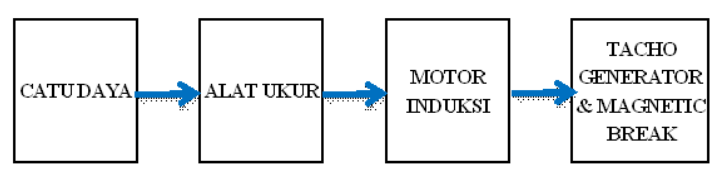

Gambar 1. Diagram Blok Pengujian

analisa pada rangkaian ekivalen[5,7]

Untuk melakukan analisa atau perhitungan rugi-rugi pada motor induksi dilakukan dengan menggunakan metode analisa pada rangkaian ekivalen[5,7] dan untuk mendapatkan nilai dari parameter yang ada pada rangkaian ekivalen perlu dilakukan beberapa pengujian antara lain:

\section{Pengujian DC}

Untuk memperoleh harga $\mathrm{R} 1$ dilakukan dengan pengukuran DC yaitu dengan menghubungkan sumber tegangan $\mathrm{DC}(\mathrm{Vdc})$ pada dua terminal input dan $\mathrm{R} 1$, arus DC-nya (Idc) lalu diukur. Di sini tidak mengalir arus rotor karena tidak ada tegangan yang terinduksi. Pada pengujian ini rangkaian dapat dihubungkan dengan hubung bintan $(\mathrm{Y})$ atau delta $(\Delta)$.Gambar rangkaian ketika kumparan motor induksi tiga phasa terhubung $\mathrm{Y}$, dan diberi suplai de dapat dilihat pada Gambar2(A). Harga $\mathrm{R}_{1} \mathrm{dc}$ dapat dihitung, untuk kumparan dengan hubungan $\mathrm{Y}$, adalah dengan menggunakan persamaan sebagai berikut :

$$
R_{1 D C}=\frac{V_{D C}}{2 I_{D C}}(\mathrm{Ohm})
$$

Pada saat kumparan terhubung delta $(\Delta)$, Gambar2(B). rangkaian untuk kumparan terhubung delta. Diketahui bahwa tahanan pada kumparan pada masing - masing phasa dianggap sama, maka $\mathrm{RA}=\mathrm{RB}=\mathrm{RC}=\mathrm{R}$ Jadi Gambar2(B) diatas dapat disederhanakan menjadi seperti Gambar2(C).

$$
\begin{array}{ll}
\text { Dimana } & : R_{P}=R_{B}+R_{C} \\
\text { Jadi } & : R_{A}=\frac{V_{D C}}{I_{A}} \\
\text { Dimana } & : \quad I_{A}=I_{D C} x \frac{R_{P}}{R_{A}+R_{P}} \Rightarrow I_{A}=\frac{2}{3} I_{D C} \\
\text { Maka } & : \quad R_{1 D C}=\frac{V_{D C}}{2 / 3 I_{D C}}=\frac{3}{2} x \frac{V_{D C}}{I_{D C}}
\end{array}
$$

Harga R1 ini dinaikkan dengan faktor pengali 1,1-1,5 untuk operasi arus bolak balik, karena pada operasi arus bolak-balik resistansi konduktor meningkat karena distribusi arus yang tidak merata akibat efek kulit dan medan magnet yang melintasi alur.

Karena besar tahanan konduktor stator dipengaruhi oleh suhu, dan biasanya bila rugi-rugi motor ditentukan dengan pengukuran langsung pada motor, maka untuk mengetahui nilai tahanan yang paling mendekati, biasanya dilakukan dengan beberapa kali pengukuran dan mengambil besar rata-rata dari semua pengukuran yang dilakukan.

\section{Pengujian Rotor Tertahan}

Pada pengujian ini motor di tahan dengan menggunakan motor induksi 3 phasa yang di beri suplai dc dan di bantu dengan tacho generator dan magnetik break yang di kopel langsung pada motor induksi yang akan di uji, seperti pada gambar 3.7. dan pada pengujian ini rotor motor tidak berhenti, hanya mengalami

Tabel 1. Hasil Pengukuran dan Perhitungan

\begin{tabular}{|c|r|c|r|c|c|c|c|c|c|}
\hline \multirow{2}{*}{$\begin{array}{c}\text { Pengat } \\
\text { uran } \\
\text { Nm }\end{array}$} & $\begin{array}{c}\text { Arus } \\
\text { I/A }\end{array}$ & $\begin{array}{c}\text { Tegangan } \\
\text { E/V }\end{array}$ & $\begin{array}{c}\text { Daya } \\
\text { P1/W }\end{array}$ & $\begin{array}{c}\text { Faktor } \\
\text { Kerja } \\
\text { Cos } \phi\end{array}$ & $\begin{array}{c}\text { Frequ } \\
\text { ennsi } \\
\text { F }\end{array}$ & $\begin{array}{c}\text { Kecepatan } \\
\text { Motor } \\
\text { RPM }\end{array}$ & $\begin{array}{c}\text { Daya } \\
\text { P2/W }\end{array}$ & $\begin{array}{c}\text { Efisiensi } \\
\eta\end{array}$ & $\begin{array}{c}\text { Slip } \\
\%\end{array}$ \\
\hline 0 & 0,7 & 390 & 80 & 0,15 & 50,2 & 1492 & 70,8 & 1,1 & 0,06 \\
\hline 0,2 & 0,7 & 390 & 100 & 0,20 & 50,2 & 1488 & 94,5 & 1,1 & 0,06 \\
\hline 0,4 & 0,7 & 390 & 120 & 0,30 & 50,2 & 1478 & 141,7 & 0,8 & 0,05 \\
\hline 0,6 & 0,7 & 390 & 140 & 0,35 & 50,2 & 1469 & 165,3 & 0,8 & 0,05 \\
\hline 0,8 & 0,75 & 390 & 160 & 0,40 & 50,2 & 1463 & 202,4 & 0,8 & 0,04 \\
\hline 1 & 0,8 & 390 & 185 & 0,49 & 50,2 & 1448 & 264,5 & 0,7 & 0,03 \\
\hline 1,2 & 0,8 & 390 & 205 & 0,51 & 50,4 & 1437 & 258,1 & 0,8 & 0,03 \\
\hline 1,4 & 0,8 & 390 & 230 & 0,56 & 50,4 & 1431 & 283,4 & 0,8 & 0,02 \\
\hline 1,6 & 0,9 & 390 & 260 & 0,60 & 50,8 & 1418 & 364,3 & 0,7 & 0,01 \\
\hline 1,8 & 0,9 & 390 & 270 & 0,64 & 50,2 & 1410 & 367,0 & 0,7 & 0,01 \\
\hline 2 & 0,9 & 390 & 300 & 0,65 & 50,2 & 1410 & 372,8 & 0,8 & 0,01 \\
\hline 2,2 & 1,0 & 390 & 330 & 0,70 & 50,2 & 1405 & 472,3 & 0,7 & 0,00 \\
\hline 2,6 & 1,3 & 390 & 390 & 0,73 & 50,2 & 1405 & 640,3 & 0,6 & 0,00 \\
\hline
\end{tabular}

perlambatan.

\section{Pengujian Beban Nol}

Pada pengujian beban nol, rangkaian pengujian dan cara pengujian sama seperti pada pengujian karakteristik kecepatan motor induksi 3 phasa hanya saja tacho generator dan magnetic break nya tidak di kopel atau tidak digunakan, akan tetapi data yang di peroleh sama dengan data pada saat pengujian pengaturan $0 \mathrm{nM}$, sehingga data yang di gunakan adalah data pada pengujian karakteristik kecepatan motor induksi pada saat pengaturan $0 \mathrm{nM}$.

\subsection{Prosedur Pengujian}

Adapun langkah-langkah yang dilakukan dalam beberapa proses pengujian adalah sebagai berikut: 
1. Merangkai rangkaian pengujian sesuai dengan gambar rangkaian tiap-tiap pengujian.

2. Memastikan bahwa semua peralatan telah siap dan aman untuk melakukan pengujian.

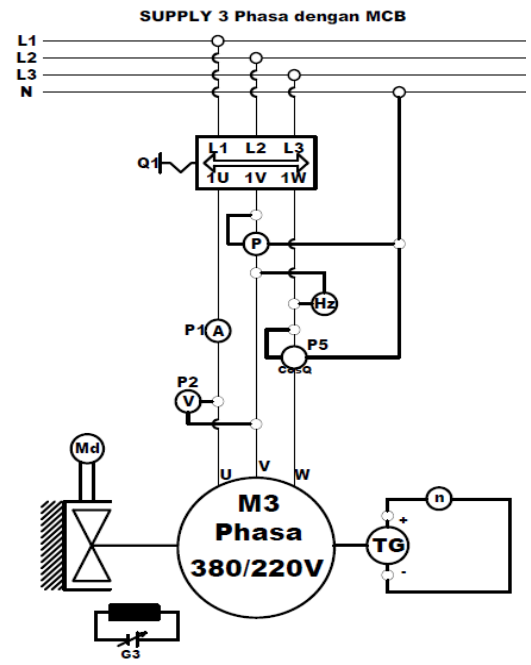

Gambar 3. Rangkaian Pengujian

3. Memastikan bahwa semua alat ukur yang terpasang dalam posisi OFF sebelum suplai tegangan di maksukan.

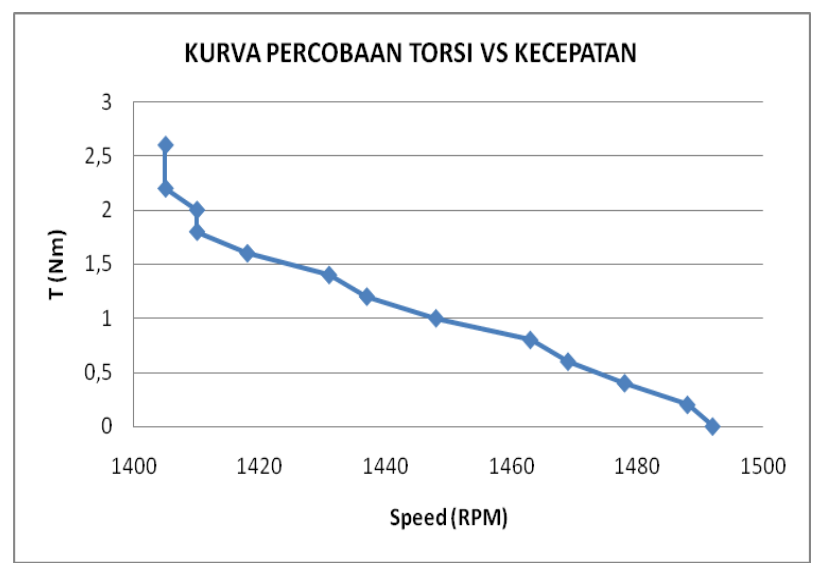

Gambar 4. Kurva Percobaan Torsi VS Kecepatan

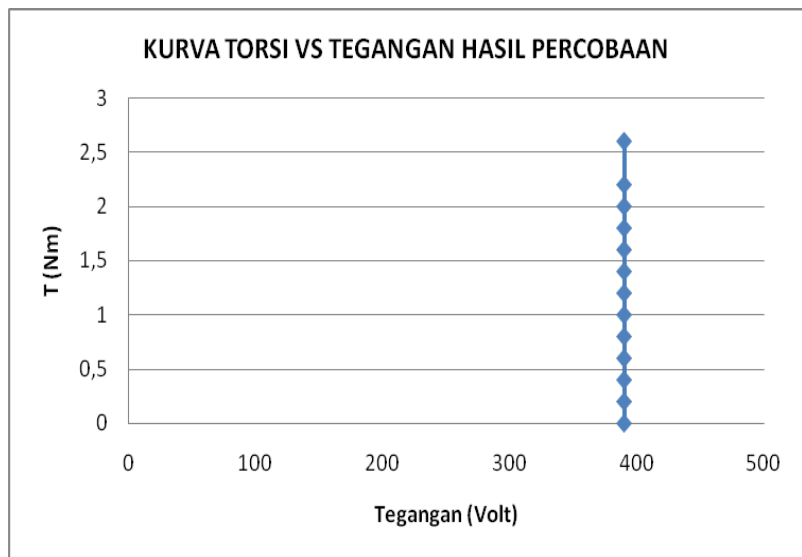

Gambar 6. Kurva Percobaan Torsi VS Tegangan
4. Menjalankan rangkain pengujian dengan cara menaikan penghubung catu daya (MCB) ke posisi ON.

5. Nyalakan semua alat ukur yang terpasang pada rangkaian dengan menekan tombol ke posisi on.

6. Lakukan pengambilan data secepat nya sebelum suhu motor yang dianalisa menjadi panas.

7. Untuk pengambilan data pengujian karakteristik kecepatan motor dilakukan berdasarkan tahapan pengaturan torsi hingga mencapai arus maksimal motor yang diuji.

8. Setelah pengambilan data selesai, matikan terlebih dahulu semua tombol alat ukur ke posisi OFF sebelum memutuskan suplai tegangan pada rangkaian pengujian.

9. Memutuskan suplai tegangan pada rangkaian pengujian, dengan cara menurunkan penghubung catu daya (MCB) ke posisi OFF.

10. Pengujian selesai data yang di peroleh di buatkan dalam tabel dan akan di analisa

\section{HASIL}

Pada pengujian ini motor di hubungkan dengan menggunakan rangkaian delta, menyesuaikan dengan supply listrik yang ada di BLK yakni 380 Volt.

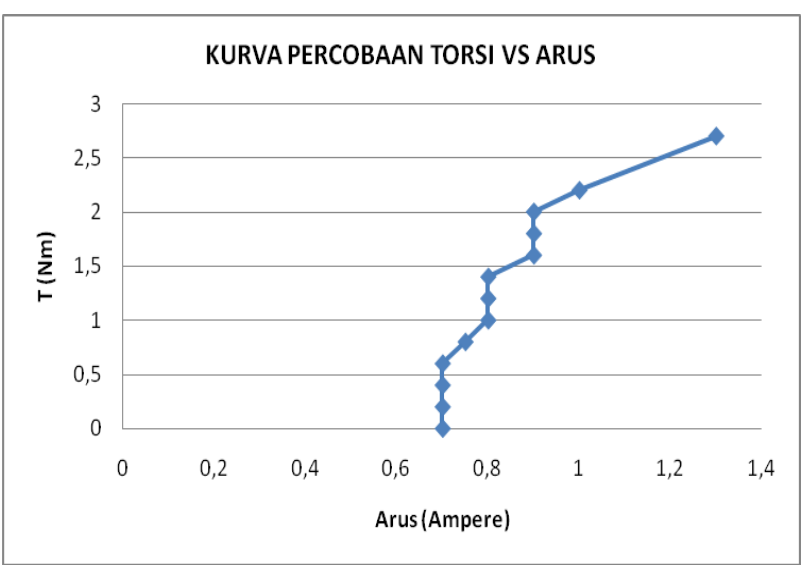

Gambar 5. Kurva Percobaan Torsi VS Arus

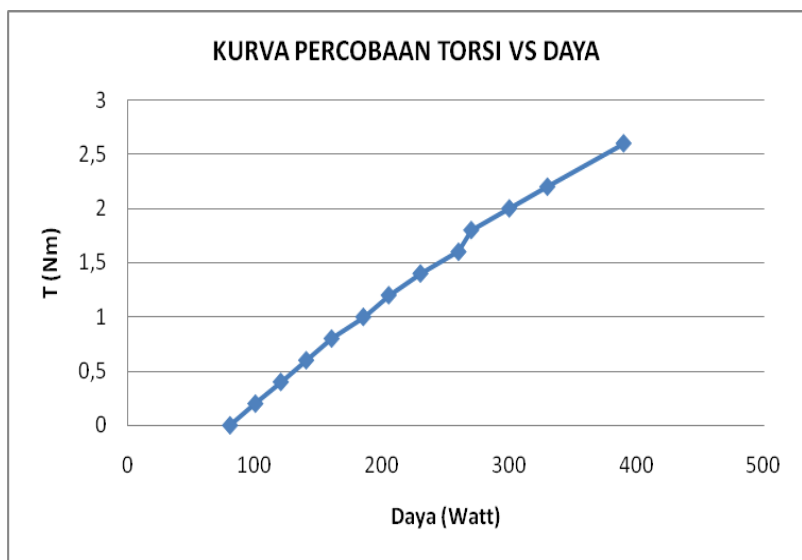

Gambar 7. Kurva Percobaan Torsi VS Daya 
Sedangkan pengujian ini dimaksudkan untuk mengetahui karakteristik kecepatan motor induksi (Asinkron) 3 phasa. Untuk dapat melakukan pengujian dan pengukuran tentunya alat ukur dan motor listrik yang akan diuji dirangkai seperti pada gambar3. Untuk mendapatkan data hasil pengukuran perlu dilakukan langkah-langkah sebagai berikut:

1. Rangkai, rangkain pengujian seperti pada gambar

2. Rangkaian dihubungkan Delta $(\Delta)$.

3. Masukan sumber arus AC 380 VoltJalankan rangkaian pengujian.

4. Catat hasil yang ditunjukan pada alat ukur Arus (I), Tegangan (V), Daya (P), $\operatorname{Cos} \varphi$, Frekwensi (f) dan putaran (n) Dan lakukan perhitungan dengan menggunakan persamaan untuk mendapatkan nilai, $\left(\mathrm{P}_{2}\right)$, efisiensi $(\eta)$ dan slip $(\mathrm{S})$.

Untuk menghitung daya $\left(\mathrm{P}_{2}\right): \quad P_{2}=\sqrt{3} \cdot V \cdot I \cdot \operatorname{Cos} \varphi$

Contoh:

Pada saat pengaturan torsi $0 \mathrm{Nm}$ nilai $\mathrm{P}_{2}$ adalah:

$$
P_{2}=\sqrt{3} \times 390 \times 0,7 \times 0,15=70,8 \mathrm{Watt}
$$

Pada saat pengaturan torsi dinaikan $1,8 \mathrm{Nm}$ nilai $\mathrm{P}_{2}$ adalah $: \mathbb{P}_{2}=\sqrt{3} \times 390 \times 0,9 \times 0,64=367 \mathrm{Watt}$

Pada saat pengaturan torsi dinaikan 2,6 Nm nilai $\mathrm{P}_{2}$ adalah $: \mathbb{P}_{2}=\sqrt{3} \times 390 \times 1,3 \times 0,73=640,3$ Watt

Untuk menghitung efisiensi $(\eta): \quad \eta=\frac{P_{2}}{P_{1}} \times 100 \%$

Contoh:

Pada saat pengaturan torsi $0 \mathrm{Nm}$ nilai $\eta$ adalah:

$$
\eta=\frac{70,8}{80} \times 100 \%=1,1
$$

Pada saat pengaturan torsi dinaikan $1,8 \mathrm{Nm}$ nilai $\eta$

$$
\text { adalah: } \quad \eta=\frac{367}{270} \times 100 \%=0,7
$$

Pada saat pengaturan torsi dinaikan 2,6 Nm nilai $\eta$ adalah: $\eta=\frac{640,3}{390} \times 100 \%=0,6$

Untuk menghitung slip (S) :S $=\frac{N_{S}-N_{Y}}{N_{S}} \times 100 \%$ Contoh:

pada saat pengaturan torsi $0 \mathrm{Nm}$ nilai $\mathrm{S}$ adalah:

$$
S=\frac{1492-1400}{1492} \times 100 \%=0,06
$$

Pada saat pengaturan torsi dinaikan $1,8 \mathrm{Nm} \mathrm{Nm}$ nilai $\mathrm{S}$

adalah $: S=\frac{1410-1400}{1410} \times 100 \%=0,01$
Pada saat pengaturan torsi dinaikan 2,6 Nm Nm nilai $\mathrm{S}$

adalah $: S=\frac{1405-1400}{1405} \times 100 \%=0$

Dari data hasil pengujian dan perhitungan pada tabel 1 . diatas dapat dibuatkan kedalam kurva karakteristik pengaturan torsi terhadap Arus (I), Tegangan (V), daya (P), dan Kecepatan putaran (RPM).

\section{PEMBAHASAN}

\subsection{Karakteristik Kecepatan Motor Induksi}

Pada gambar 4 di atas menjelaskan tentang bagaimana hubungan antara torsi motor dengan kecepatan. Untuk pengukuran pada kecepatan motor, perubahan kecepatan yang terjadi tidak terlalu besar pada setiap peningkatan torsi per $0,2 \mathrm{Nm}$, akan tetapi tetap berpengaruh terhadap perubahan kecepatan motor, seperti yang terlihat pada gambar 4 pada saat pengaturan torsi dari $0 \mathrm{Nm}-2,6 \mathrm{Nm}$ kecepatan motor menurun dari 1492 RPM - 1405 RPM, dari pengukuran ini terlihat bahwa semakin besar torsi motor maka kecepatan motor akan semakin kecil, sehingga dapat dikatakn hubungan antar torsi motor dengan kecepatan berbanding terbalik.

Hubungan kecepatan motor (RPM) dengan torsi (Nm) berdasarkan rumus atau persamaan adalah $\mathrm{P}=\omega \times \mathrm{T}$, jika daya (P) dianggap konstan maka besarnya torsi tergantung dari kecepatan sudut $(\omega)$.

$\omega=2 \pi \frac{n}{60}$

Jika putaran rotor dipercepat, maka torsi yang dihasilkan kecil, dan sebaliknya jika torsinya besar maka kecepatannya lambat, dari gambar 4. di atas terlihat bahwa kecepatan maksimum motor induksi berada pada saat torsi 2,6 Nm kecepatan motor 1405 RPM.

Dengan menggunakan data pengukuran pada tabel 1 . dan di terapkan pada persamaan di atas maka torsi dapat di tentukan berdasarkan dengan persamaan:

kenaikan 0,05 Ampere, motor menyerap arus maksimum 
Tabel 2 Hasil Perhitungan Torsi (Nm)

\begin{tabular}{|l|c|c|c|c|c|c|c|c|c|c|c|c|c|}
\hline Daya (P) Watt & 80 & 100 & 120 & 140 & 160 & 185 & 205 & 230 & 260 & 270 & 300 & 330 & 390 \\
\hline Kecepatan (n) RPM & 1492 & 1488 & 1478 & 1469 & 1463 & 1448 & 1437 & 1431 & 1418 & 1410 & 1410 & 1405 & 1405 \\
\hline Torsi (T) Nm & 0,5 & 0,6 & 0,8 & 0,9 & 1 & 1,2 & 1,4 & 1,5 & 1,8 & 1,8 & 2 & 2,2 & 2,7 \\
\hline
\end{tabular}

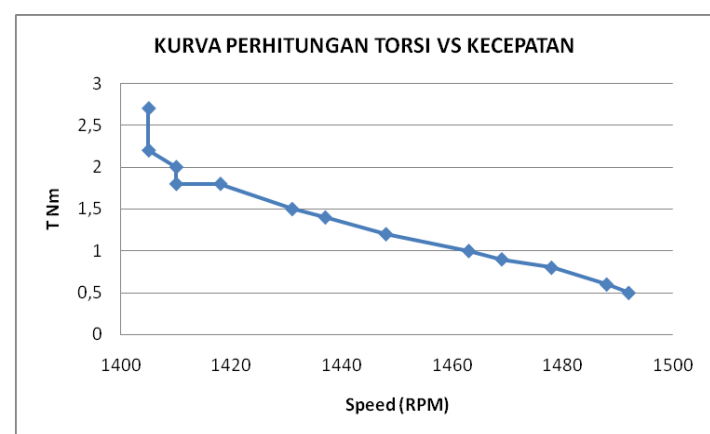

Gambar 8. Kurva Torsi VS Kecepatan Hasil Perhitungan

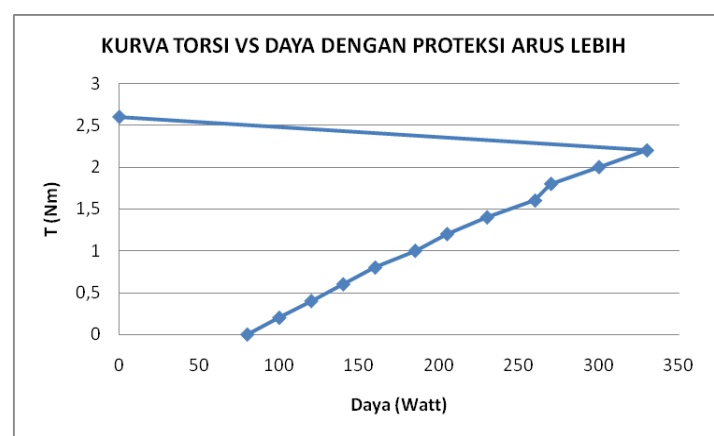

Gambar 10. Kurva Torsi VS Daya Dengan Proteksi Arus lebih

$$
T=\frac{P}{\omega} \gg \omega=2 \pi \frac{n}{60}
$$

Sehingga pada saat daya $(P)=80$ Watt dan Kecepatan $(n)$ 1492 RPM, maka torsi Adalah :

$$
T=\frac{80}{2 x a_{1} 14 x \frac{1402}{60}}=\frac{80}{156,16}=0,5 \mathrm{Nm}
$$

dengan demikian diperoleh data seperti pada Tabel2, dan dari data pada tabel 2. jika di bandingkan dengan Tabel 1. maka terlihat adanya perbedaan, namun hubungan antar kecepatan dan torsi tetap sama yakni berbanding terbalik dan data pada tabel 2. dapat digambarkan ke dalam kurva seperti Gambar8.

Pada gambar 5. arus motor berbanding lurus terhadap vareasi pengaturan torsinya, pada saat motor di jalankan posisi pengaturan torsi pada $0 \mathrm{Nm}$ daya $(\mathrm{P})$ yang di hasilkan 80 Watt, menyerap arus (I) 0,7 Ampere dan kecepatan nya (n) 1492 RPM, torsi dinaikan 0,2 Nm sampai 0,6 Nm arus motor tidak mengalami perubahan hanya daya (P) dan kecepatan (n) yang mengalami perubahan namun arus yang di serap tetap sama yaitu 0,7 Ampere, pada saat torsi mencapai $0,8 \mathrm{Nm}$ arus hanya mengalami kenaikan 0,05 Amper, sama halnya pada saat
Tabel Hasil Perhitungan Daya (P)

\begin{tabular}{|l|c|c|c|c|c|c|c|c|c|c|c|c|c|}
\hline Daya (P) Watt & 0 & 31,1 & 61,9 & 92,3 & 123 & 152 & 180 & 210 & 237 & 266 & 295 & 324 & 382 \\
\hline Kecepatan (n) RPM & 0 & 1488 & 1478 & 1469 & 1463 & 1448 & 1437 & 1431 & 1418 & 1410 & 1410 & 1405 & 1405 \\
\hline Torsi(T) Nm & 0 & 0,2 & 0,4 & 0,6 & 0,8 & 1 & 1,2 & 1,4 & 1,6 & 1,8 & 2 & 2,2 & 2,6 \\
\hline
\end{tabular}

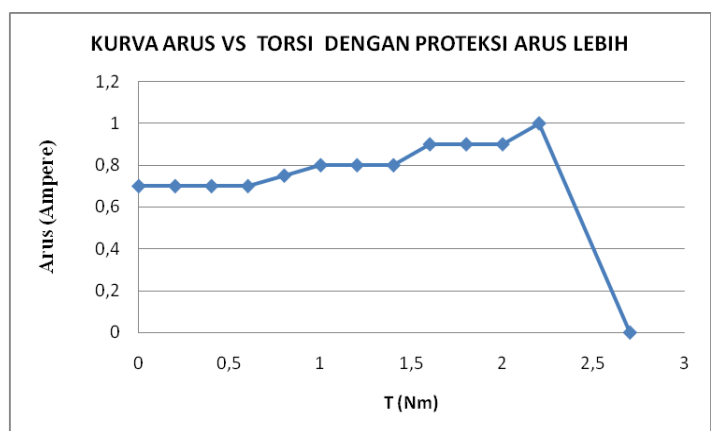

Gambar 9. Kurva Torsi VS Kecepatan Hasil Perhitungan

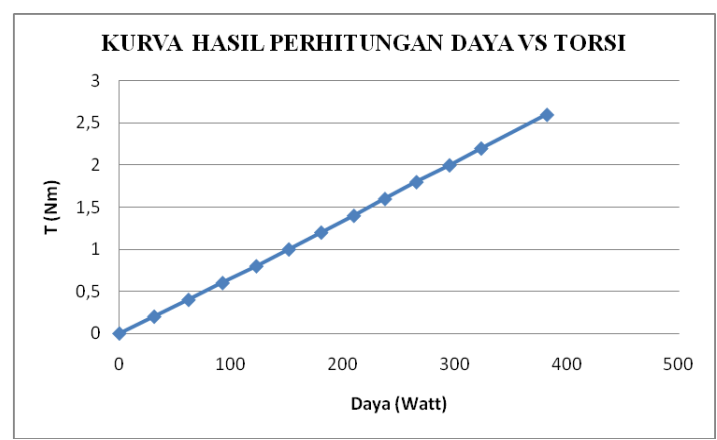

Gambar 11. Kurva Daya VS Torsi Hasil Perhitungan

torsi dinaikan $1 \mathrm{Nm}-1,4 \mathrm{Nm}$ arus yang diserap motor induksi masi sama yaitu 0,8 Ampere hanya mengalami kenaikan 0,05 Ampere, motor menyerap arus maksimum nya pada saat torsi di naikan menjadi 2,2 $\mathrm{Nm}$ sesuai dengan arus maksimum yang ada pada data name plate motor yang dianalisa, pada saat arus motor mencapai nilai maksimum motor seharus nya berhenti dan pengaturan torsi berhenti.akan tetapi motor yang di analisa masi tetap beroprasi pada saat torsi dinaikan mencapai 2,6 Nm dengan kondisi bodi motor semakin memanas, jika hal ini terus di biarkan yang dikhawatirkan akan terjadi kerusakan pada motor yang di analisis. Oleh karena itu perlunya di tambahkan sistem proteksi, yang memproteksi arus lebih pada rangkaian percobaan sehingga pada saat motor mencapai arus maksimum nya motor akan berhenti dan arus motor akan turun ke posisi nol, seperti yang di tunjukan pada gambar 9. Untuk Tegangan suplay motor yang di analisa relatif stabil tidak terpengaruh dengan adanya pengaturan torsi, dari $0 \mathrm{Nm}-2,6 \mathrm{Nm}$ tegangan terukur adalah 390 Volt, sehingga kurva yang terbentuk hanya berupa garis lurus, seperti terlihat pada gambar 6. di atas.

Kurva daya $(\mathrm{P} 1)$ yang terukur pada percobaan ini hanya mengalami penambahan \pm 20 Watt per $0,2 \mathrm{Nm}$ nya. Seperti yang di tunjukan pada gambar 7. sama seperti arus yang mana kurva yang terbentuk berbanding 
lurus dengan variasi pengaturan torsi nya hanya saja daya maksimum yang terukur tidak sesuai dengan arus maksimum motor, pada saat arus mencapai 1 Amper daya yang terukur hanya 330 Watt, ketika daya mencapai kenaikan 0,05 Ampere, motor menyerap arus maksimum 390 Watt arus motor melebihi dari arus maksimum nya yakni 1,3 Ampere, seharus nya pada saat pengaturan torsi 2,2 $\mathrm{Nm}$ arus mencapai 1 Ampere dan daya mencapai 370 Watt, jika ditambahkan rangkaian sistem proteksi seperti pada pembahasan kurva arus vs torsi maka motor akan beroprasi pada saat daya mencapai 330 Watt, karena pada posisi ini arus motor sudah mencapai 1 Ampere, dan kurva yang terbentuk seperti yang di perlihatkan pada 9.

Hubungan daya motor dengan torsi $(\mathrm{Nm})$ berdasarkan rumus atau persamaan adalah $\mathrm{P}=\omega \mathrm{x} \mathrm{T}$, jika persamaan ini digunakan untuk membandingkan hasil pengukuran dengan perhitungan menggunakan rumus maka akan terjadi perbedaan seperti halnya pada pembahasan kurva kecepatan vs torsi, data hasil perhitungan dapat dilihat pada tabel 3, sedangkan kurva yang terbentuk dapat di lihat pada gambar 10 .

\subsection{Rugi-Rugi Daya Pada Motor Induksi}

Untuk mendapatkan rugi-rugi pada motor induksi (asinkron) 3 phasa, biasa nya dilakukan dengan cara analisis pada rangkaian ekivalen motor induksi (asinkron) 3 phasa, rangkaian ekivalen motor induksi sendiri terbagi atas dua rangkaian yakni rangkaian ekivalen sisi rotor, dan rangkaian ekivalen pada sisi stator. Dalam penulisan tugas akhir ini penulis akan menggunakan rangkaian ekivalen pendekatan seperti yang terlihat pada Gambar 12. yang akan dianalisa antara laian adalah: rugi inti stator $\left(\mathrm{P}_{\mathrm{C}}\right)$, rugi tembaga stator $\left(\mathrm{P}_{\mathrm{SCL}}\right)$, rugi daya celah udara $\left(\mathrm{P}_{\mathrm{AG}}\right)$, Rugi tembaga rotor

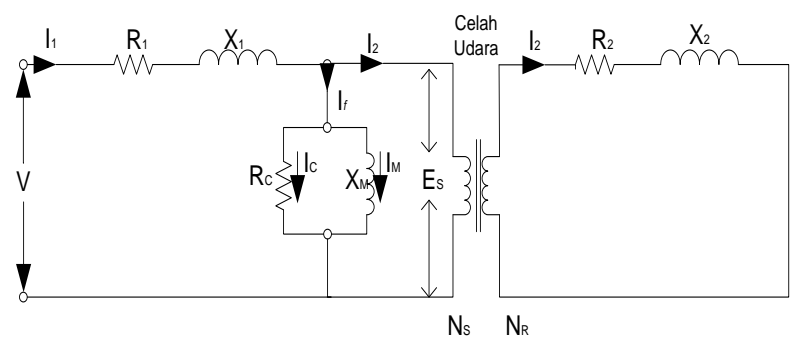

Gambar 12. Rangkaian Ekivalen Lengkap Motor Induksi 3 Phasa

$\left(\mathrm{P}_{\mathrm{RCL}}\right)$ dan daya mekanik $\left(\mathrm{P}_{\mathrm{Mek}}\right)$.

Dimana:
$\mathrm{V}=$ Tegangan Suplai
R2 = Hambatan Rotor
ES = Tegangan Induksi Stator
$\mathrm{X} 1$ = Reaktansi Stator
$\mathrm{ER}=$ Tegangan Induksi Stator
$\mathrm{X} 2$ = Reaktansi Rotor
NS = Lilitan Stator
IS = Arus Stator
$\mathrm{NR}=$ Lilitan Rotor
$\mathrm{IR}=$ Arus Rotor
R1 = Hambatan Stator
IM =Arus Magnetisasi

Untuk mempermudah perhitungan maka rangkaian ekivalen pada gambar 12. dapat dilihat dari sisi stator, rangkaian ekivalen motor induksi tiga phasa akan dapat digambarkan seperti Gambar 13.

\section{Percobaan Resistansi DC (DC TEST)}

Tujuan dari percobaan ini adalah untuk mendapatkan nilai resistansi stator motor $\mathrm{R}_{1}$, dengan cara merangkai rangkaian percobaan seperti pada gambar 14. motor terhubung dengan rangkaian delta $(\Delta)$ dan diberi suplai tegangan DC. Data dan hasil dari percobaan test DC adalah :

$$
\begin{aligned}
& \text { VDC }=46 \text { Volt } \\
& \text { IDC }=1,2 \text { Ampere }
\end{aligned}
$$

Seperti yang telah dijelaskan sebelumnya belitan stator motor induksi rotor sangkar terhubung delta sehingga persaman yang dipakai untuk menghitung RDC adalah: $R_{D C}=\frac{a \times 48}{2 \times 1, a}=\frac{144}{2,6}=55,4 \Omega$

Karena besaran tahanan konduktor stator dipengaruhi oleh suhu, dan biasanya bila rugi-rugi motor ditentukan dengan pengukuran langsung pada motor, maka untuk mengetahui nilai tahanan yang paling mendekati, biasanya dilakukan dengan beberapa kali pengukuran dan mengambil besar rata-rata dari semua pengukuran yang dilakukan. Untuk mendapatkan harga $R 1$ ini RDC dinaikkan dengan factor pengali 1,1 - 1,5 untuk operasi arus bolak-balik, karena pada operasi arus bolak-balik resistansi konduktor meningkat karena distribusi arus

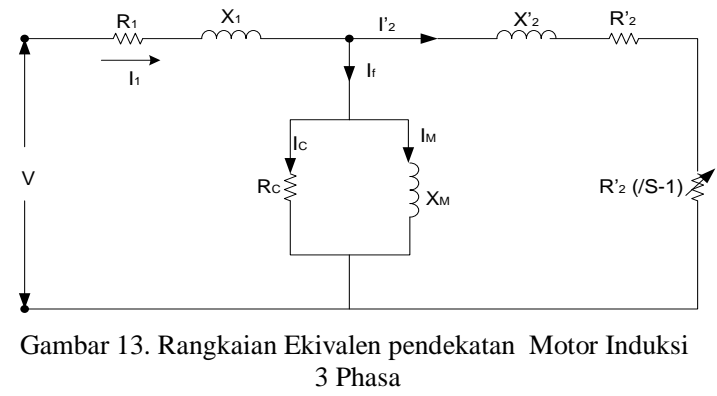

yang tidak merata dan medan magnet yang melintasi alur. Sehingg didapat R1 $=\mathrm{RDC} \times 1,1=55,4 \times 1,1=$ $60,9 \Omega$.

\section{Percobaan Rotor Tertahan (Blocked Rotror Test)}

Pada pengukuran ini rotor motor sangkar di tahan dengan menggunakan motor induksi rotor sangkar dengan suplai tegangan DC, sehingga motor rotor sangkar yang terhubung DC secara tidak langsung 
menahan perputaran motor rotor sangkar yang di beri suplai tegangan AC namun pada percobaan ini motor rotor sangkar yang di suplai tegangan AC tidak sampai berhenti.

Dari hasil percobaan di atas di peroleh data-data sebagai berikut:

$$
\begin{aligned}
& \mathrm{PBR}=270 \text { Watt } \\
& \mathrm{IBR}=1,2 \text { Ampere } \\
& \mathrm{VBR}=195 \text { Volt }
\end{aligned}
$$

Sehingga dapat di hitung:

$$
\begin{aligned}
& R_{\theta}=\frac{P_{B R}}{3 x I_{B R}^{2}}=\frac{270}{3 \times 1,2^{2}}=\frac{270}{4,32}=62,5 \Omega \\
& Z_{\theta}=\frac{V_{B R}}{\sqrt{3} x I_{B R}}=\frac{195}{\sqrt{3} \times 1,2}=\frac{195}{2,1}=92,85 \\
& X_{\theta}=\sqrt{Z_{\theta}^{2}-R_{\theta}^{2}}=\sqrt{92,85^{2}-62,5^{2}}=\sqrt{4715}=68,67 \Omega \\
& R_{2}^{s}=R_{\theta}-R_{1}=62,5-60,9=1,6 \Omega
\end{aligned}
$$

Mesin induksi $0,3 \mathrm{~kW}$ ini termasuk mesin induksi kelas $\mathrm{B}$, sehingga $\mathrm{X} 1=0,4 \mathrm{Xbr}$ dan $\mathrm{X}^{\prime} 2=0,6 \mathrm{Xe}$, sehingga:

$$
\begin{aligned}
& \mathrm{X} 1=0,4 \mathrm{Xe}=0,4 \times 68,67=27,5 \Omega \\
& \mathrm{X}^{\prime} 2=0,6 \mathrm{Xbr}=0,6 \times 68,67=41,2 \Omega
\end{aligned}
$$

\section{Percobaan Tanpa Beban (No Load Test)}

Hasil percobaan tanpa beban nol sama dengan data percobaan pada tabel 1. pada saat pengaturan $0 \mathrm{nM}$ adalah:

$\mathrm{I}_{\mathrm{O}}=0,7$ Ampere

$\mathrm{V}_{\mathrm{O}}=390$ Volt

$\mathrm{P}_{\mathrm{O}}=80 \mathrm{Watt}$

$I_{\varphi}=\frac{P_{0}}{\sqrt{3} V_{0} I_{0}}=\frac{80}{\sqrt{3} \times 390 \times 0,7}=0,16$

$I_{2}^{s}=I_{0}-I_{\mp}=0,7-0,17=0,52$ Apere

$X_{\mathrm{m}}=\frac{V_{0}}{\sqrt{3} I_{0}}=\frac{390}{\sqrt{3} \times 0,7}=\frac{390}{1,21}=225 \Omega$

Dari ke tiga percobaan di atas diperoleh data-data sebagai berikut:

$\begin{array}{lll}\mathrm{R}_{1}=60,9 \Omega & \mathrm{R}_{\mathrm{e}}=62,5 \Omega & \mathrm{Z}_{\mathrm{e}}=92,85 \Omega \\ \mathrm{X}_{\mathrm{e}}=68,67 \Omega & \mathrm{R}_{2}=1,6 \Omega & \mathrm{X}_{\mathrm{m}}=225 \Omega \\ \mathrm{X}_{1}=27,5 \Omega & \mathrm{X}^{\prime}{ }_{2}=41,2 \Omega & \mathrm{I}_{2}=0,52 \mathrm{~A}\end{array}$

(PMek) daya mekanis keluaran (output) (Watt) PCONVERSI. Dengan menggunakan persamaan berikut:

1. Rugi-rugi tembaga pada belitan stator (Watt). $P_{\text {SCL }}=3 I_{1}^{2} x R_{1}=3 \times 0,7^{2} \times 60,9=89,5$ Watt

2. Rugi - rugi inti pada stator (Watt).

$$
P_{C}=P_{0}-I_{0}^{2} x R_{1}=86-0,7^{2} x 60,9=56,2 \text { Watt }
$$

3. Rugi-rugi tembaga pada belitan rotor (watt)

$$
P_{\text {RCL }}=3\left(I_{2}^{s}\right)^{2} R_{2}^{s}=3 x 0,52^{2} x 1_{x} 6=1,3 \text { Watt }
$$

4. Daya celah udara

$$
P_{A G}=3\left(I_{2}^{s}\right)^{2} \frac{R_{2}^{s}}{s}=3 x 0,52^{2} \frac{1,6}{0,06}=21,6 \mathrm{Watt}
$$

5. Daya Conversi

$$
\begin{aligned}
& P_{\text {CoNV }}=3\left(I_{2}^{s}\right)^{2}\left(\frac{1-s}{s}\right) R_{2}^{s}=3 x 0,52^{2}\left(\frac{1-0,06}{0,06}\right) 1,6 \\
& =0,81 \times 15,7 \times 1,6=20,3 \mathrm{Watt}
\end{aligned}
$$

6. Daya Mekanik

$$
\begin{aligned}
& P_{\text {Mek }}=3 I_{2}^{s} R_{2}^{s}\left(\frac{1-s}{s}\right)=3 x 0,52^{2} \times 1,6 x\left(\frac{1-0,06}{0,06}\right) \\
& =0,81 x 1_{s} 6 x 15,7=20,34 \text { Watt }
\end{aligned}
$$

\section{KESIMPULAN}

Motor yang di analisa adalah motor induksi 3 phasa type rotor sangkar karena keterbatasan suplai/sumber tegangan yang tersedia sehingga pada pengujian ini rangkaian pengujian dihubung $\operatorname{delta}(\Delta)$.

Karena keterbatasan alat yang ada maka pada analisa ini, motor yang digunakan adalah motor dengan kapasitas yang kecil, sehingga data yang di tunjukan pada alat ukur perubahan nya juga sangat kecil pada setiap perubahan/pengaturan torsi.

Kecepatan motor induksi pada saat $0 \mathrm{nM} 1492$ RPM dan terus mengalami penurunan pada saat pengaturan torsi di naikan per $0,2 \mathrm{Nm}$, sampai mencapai 2,6 Nm kecepatan motor induksi 1405 RPM, hampir mencapai 1400 RPM sesuai dengan name plate, pada motor yang di analisa.

Pada saat pengaturan torsi mencapai 2,6 $\mathrm{Nm}$ arus motor mencapai 1,3 Ampere, daya yang terukur 390 Watt dan kecepatan motor 1405 RPM, arus dan daya motor sudah melebihi dari kapasitas pada name plate motor sedangkan kecepatan motor belum mencapai kapasitas nya, akan tetapi suara yang di timbulkan dari putaran motor semakin kencang dan suhu bodi motor semakin panas, untuk menjaga agar motor tidak rusak/terbakar percobaan di hentikan sampai pada pengaturan 2,6 Nm.

Tacho generator dan magnetic powder break yang dikopel pada motor induksi yang dianalisa juga berfungsi sebagai pembebanan pada saat melakukan pengujian karakteristik kecepatan motor induksi rotor sangkar. 


\section{REFERENSI}

1. Kadir A, Mesin Tak Serempak, Djambatan, Jakarta, 1981.

2. Eugene C. Lister, Hanapi Gunawan, Mesin Dan Rangkaian Listrik, Erlangga, Jakarta, 1993.

3. Sumanto, Motor Listrik Arus Bolak-Balik, Endi Offset, Yogyakarta, 1993.

4. Zuhal. Dasar Teknik Tenaga Listrik dan Elektronika Daya. PT gramedia Pustka Utama. Jakarta. 1995.

5. Fizgerald, Kingsley, Umans, Mesin - Mesin Listrik, Erlangga, Jakarta, 1997.

6. Abdul Kadir, Transformator, Universitas Indonesia, 2010.

7. Sdaryatno sudirham, Analisi Rangkaian Listrik Jilid 3, Darpublic, Kanayakan D-30, Bandung, 40135. 2012.

8. www.darpublic.com.

9. http://image.slidesharecdn.com/mesinarusbolakbalik bahankuliah-120620054533-phpapp01/95/slide-1728.jpg?1340189217

10. luqman96.files.wordpress.com/2009/07/motor-acasinkron-3-f.doc

11. pakendy.weebly.com/uploads/2/4/5/6/.../prinsip_indu ksi_mtr.ppt

12. www.e-bookspdf.org > Download.

13. (http://imroee.wordpress.com/2010/01/26/thehistory-of-electric-motor/\#more-95)

14. (http://sejarahkecildunia.blogspot.com/2012/06/sejar ah-penemuan-motor listrik.html\#sthash.n9a8C8rF.dpuf). 